\title{
NORMAS FUNDAMENTAIS DO PROCESSO CIVIL: A SINTONIA DA CONSTITUIÇÃO FEDERAL E O NOVO CÓDIGO DE PROCESSO CIVIL NA GARANTIA E DEFESA DOS DIREITOS FUNDAMENTAIS
}

\author{
FUNDAMENTAL RULES OF CIVIL PROCEDURE : THE TUNING OF THE \\ FEDERAL CONSTITUTION AND THE NEW CODE OF CIVIL PROCEDURE IN \\ THE GUARANTEE AND PROTECTION OF FUNDAMENTAL RIGHTS
}

\author{
${ }^{1}$ Fernanda Sell de Souto Goulart Fernandes \\ ${ }^{2}$ Denise S. S. Garcia
}

\section{RESUMO}

Em 16 de março de 2015 foi sancionada a Lei 13.105. Conhecido por ter a intenção de redemocratizar o processo, o novo Código de Processo Civil inovou em muitos aspectos, e um deles que se destaca é a introdução ao texto legal dos já constitucionalmente previstos Princípios Processuais Constitucionais. A atitude do legislador de positivar na Legislação Ordinária os Princípios já estabelecidos na Constituição Federal só concretiza a onda de constitucionalização dos direitos. E o Processo Civil não poderia ser avesso a tal tendência. Assim, o presente artigo tem como objetivo analisar as normas fundamentais do processo civil.

Palavras-chave: Normas fundamentais, Código de processo civil, Princípios constitucionais, Direitos fundamentais

\begin{abstract}
On March 16th, 2015 was enacted Law 13,105. Known for having the intention to democratize the process, the new Civil Procedure Code innovated in many ways, and one of those that highlights is the introduction on the legal text of the Procedure Constitutional Principles, already provide in the Constitution. The legislator's attitude positivate in the Ordinary legislation the constitutional principles only embodies the wave of constitutionalization of rights. And the Civil Procedure could not be averse to this trend. Thus, this article aims to analyze the basic rules of civil procedure.
\end{abstract}

Keywords/Palabras-claves/Mots-clés: Fundamental rules, Civil procedure code, Constitutional principles, Fundamental rights

\section{INTRODUÇÃOO}

\footnotetext{
1 Doutoranda pela Universidade do Vale do Itajaí. Professora do Curso de Direito da Universidade do Vale do Itajaí. Universidade do Vale do Itajaí - UNIVALI, Santa Catarina. Brasil - E-mail: nanda goulart@univali.br 2 Doutora pela Universidade de Alicante na Espanha. Coordenadora de pós graduação lato sensu em Direito Processual Civil da Universidade do Vale do Itajaí. Universidade do Vale do Itajaí - UNIVALI, Santa Catarina. Brasil - E-mail: denisegarcia@univali.br
} 
O presente artigo abordará as normas fundamentais dispostas no Capítulo 1 do Novo Código de Processo Civil que entrará em vigor no primeiro semestre de 2016. Mostrará que a novel legislação buscou entrar em compasso com o já disposto pela Carta Magna de 1988, quando esta última disciplinou em seu texto diversos princípios processuais dando a eles status de Direito Fundamental.

Diante disso, o objetivo geral do presente artigo, é destacar as normas fundamentais elencadas no Novo Código de Processo Civil.

Os objetivos específicos são: analisar os direitos fundamentais na Constituição Federal de 1988, discorrer brevemente sobre a teoria dos princípios e regras, analisar os princípios processuais constitucionais e por fim, elencar as normas fundamentais dispostas no Capítulo I da Lei 13.105/2015.

O artigo está estruturado em quatro seções, estruturadas para atender aos objetivos propostos.

Em relação à Metodologia na Fase de Investigação ${ }^{1}$ foi utilizado o Método Indutivo ${ }^{2}$, no momento de Tratamento de Dados o Método Cartesiano, e, o Relatório dos Resultados elaborado na base lógica indutiva ${ }^{3}$.

Para operacionalizar a Pesquisa foram acionadas Categorias ${ }^{4}$, do Conceito Operacional $^{5}$ e da Pesquisa Bibliográfica ${ }^{6}$.

\section{DIREITOS FUNDAMENTAIS NA CONSTITUIÇÃO FEDERAL DE 1988}

O constituinte de 1988 privilegiou o catálogo de direitos e garantias fundamentais. Logo no início do texto constitucional são dispostos direitos que não se resumem àquelas pretensões de caráter individual, mas também àquelas de caráter coletivo, e não apenas as pertencentes à dimensão estritamente liberal, mas igualmente as de cunho social.

Ferrajoli sustenta que os direitos fundamentais, correspondem a interesses e expectativas de todos, formando o fundamento e o parâmetro da igualdade jurídica ou dimensão "substancial" da democracia".

Em uma concepção formal, os Direitos Fundamentais são “os direitos atribuídos por um ordenamento jurídico a todas as pessoas físicas enquanto tais, ou enquanto cidadãs ou enquanto capazes de agir." 8 
Pisarello relaciona o conceito e a importância dos Direitos Fundamentais com a importância da Constituição, ao prever que os Direitos Fundamentais são os interesses ou necessidades que assumem maior relevância dentro de um ordenamento jurídico determinado, sendo que uma demonstração desta relevância é a sua inclusão nas normas de maior valor dentro de um ordenamento, como são as Constituições. ${ }^{9}$

Nessa sistemática, o legislador cuidou de estabelecer mecanismos processuais eficazes de proteção desses direitos. A mera positivação de um denso catálogo de direitos fundamentais poderia torna-los meros símbolos se não estivesse acompanhada de normas de organização e procedimento destinadas à sua proteção.

\section{BREVES CONSIDERAÇÕES SOBRE PRINCÍPIOS}

Prefacialmente há que se considerar que Princípios são espécies de normas. Sendo assim tem-se o gênero normas jurídicas, dentre as quais existem duas espécies uma delas que são os Princípios e a outra que são as regras.

Luís Roberto Barroso ${ }^{10}$ traz uma separação das normas como normas-princípio e normas- disposição.

As normas-disposição, também referidas como regras, têm eficácia restrita às situações específicas às quais se dirigem. Já as normas-princípio, ou simplesmente princípios, tem, normalmente, maior teor de abstração e uma finalidade mais destacada dentro do sistema.

Segundo José Joaquim Gomes Canotilho' ${ }^{11}$ :

A teoria da metodologia jurídica tradicional distingue entre as normas e princípios (norm-Prinzip, Principles-rules, Norm und Grundesatz). Abandonar-se-á aqui essa distinção para, em substituição, se sugerir: (1) as regras e princípios são duas espécies de normas; (2) a distinção entre regras e princípios é uma distinção entre duas espécies de normas.

Os doutrinadores que dizem haver contraposição entre princípios e normas assim sustentam com o único objetivo de negar que certos princípios expressos tivessem valor vinculante para os órgãos de aplicação. ${ }^{12}$

José Joaquim Gomes Canotilho ${ }^{13}$ traz alguns critérios para tentar distinguir o que sejam regras e princípios, ambos inseridos no super conceito norma. 
a) Grau de abstração: os princípios são normas com um grau de abstracção relativamente elevado; de modo diverso, as regras possuem uma abstracção relativamente reduzida;

b) Grau de determinalidade na aplicação do caso concreto: os princípios, por serem vagos e indeterminados, carecem de mediações concretizadoras (do legislador, do juiz), enquanto as regras são susceptíveis de aplicação directa;

c) Carácter de fundamentalidade no sistema das fontes de direito: os princípios são normas de natureza estruturante ou com um papel fundamental no ordenamento jurídico devido à sua posição hierárquica no sistema das fontes (ex: princípios constitucionais) ou à sua importância estruturante dentro do sistema jurídico (ex: princípio do Estado de Direito);

d) Proximidade da ideia de direito: os princípios são 'standards' juridicamente vinculados radicados nas exigências de 'justiça' (Dworkin) ou na 'ideia de direito' (Larenz); as regras podem ser normas vinculadas com um conteúdo meramente funcional;

e) Natureza normogenética: os princípios são fundamentos de regras, isto é, são normas que estão na base ou constituem a ratio de regras jurídicas, desempenhando, por isso, uma função normogenética fundamentante.

Riccardo Guastini ${ }^{14}$ também traz algumas propriedades que devem ser observadas para que uma norma possa ser merecedora do nome "princípio".

(1) São as normas considerados pelo legislador, pela doutrina e/ou pela jurisprudência como fundamento de um conjunto de normas, portanto, a questão de se uma norma tem ou não tem valor de 'princípio' não é uma questão de fato, e a resposta é sempre opinável;

(2) Os princípios também diferenciam-se das normas na sua formulação lingüistica, pois as normas teriam um significado relativamente preciso, enquanto que os princípios possuam um significado elástico e/ou indeterminado, ou seja, os princípios são, habitualmente normas bastante vagas.

(3) Por fim os princípios caracterizam-se pela generalidade, diverso do que ocorrer com as outras normas.

Esses princípios podem ser divididos em expressos e não expressos. Os expressos são os explicitamente formulados numa adequada disposição constitucional ou legislativa. Já os não expressos são desprovidos de disposição, ou seja, não estão explicitamente formulados em alguma disposição constitucional ou legislativa, mas elaborados ou "construídos" por intérpretes. ${ }^{15}$ 
Existem outras classificações trazidas pela doutrina acerca dos princípios, destacandose a divisão feita por Paulo Márcio Cruz e Rogério Zel Gomes ${ }^{16}$ quando trata de princípios constitucionais: (a) os político- ideológicos, (b) os fundamentais gerais e (c) os específicos. Essa divisão tem relevância no caso da presente pesquisa, eis que o Direito ambiental é uma matéria constitucional indireta.

Os políticos ideológicos são aqueles que possuem dimensão axiológica fundamental, pode-se dizer os que funcionam como "princípios dos princípios". Os fundamentos gerais possuem um grau de concretude e aplicabilidade mais elevados. Por fim os específicos são aqueles que orientam uma determinada parte do Direito Constitucional, assim a maioria das matérias neles especificadas combinam com ramos do Direito. ${ }^{17}$

De todo exposto percebe-se claramente a diferença existente entre regras e princípios, sendo esses segundos os que serão tratados na sequência do presente artigo científico.

\section{PRINCÍPIOS PROCESSUAIS CONSTITUCIONAIS}

Constituições democráticas modernas contêm dois tipos ou categorias de normas. À primeira categoria pertencem aquelas normas que constituem e organizam a dação de leis, o Poder Executivo e a jurisdição, portanto, o Estado. Na segunda categoria caem aquelas normas que limitam e dirigem o Estado. Aqui devem ser mencionados, em primeiro lugar, os direitos fundamentais. Existem duas construções de direitos fundamentais. A primeira pode ser denominada “construção de regras", a segunda "construção de princípios". ${ }^{18}$

Os princípios constitucionais ocupam-se especificamente com a conformação do próprio processo, assim entendido o método de atuação Rui Portanova ${ }^{19}$ propõe uma classificação dos Princípios informadores do Processo

Civil, a partir de três graus.

Os Princípios informativos do Processo, ou de terceiro grau, correspondem às normas ideais da prestação jurisdicional, portanto dotados de forte conteúdo ético.

O primeiro deles, o lógico, estabelece que o Processo deva pautar-se em atos e formas aptos a descortinarem a verdade e evitar o erro. O princípio econômico, por sua vez, visa 
reconhecer o direito com o menor gravame possível; e o princípio político objetiva configurar o Processo como espaço de participação do cidadão para a tutela de Direitos Fundamentais.

O princípio jurídico ou da isonomia relaciona-se à promoção da igualização das condições formais e materiais entre as partes e o da instrumentalidade preleciona que "o processo deve cumprir seus escopos jurídicos, sociais e políticos, garantindo pleno acesso ao Judiciário, utilidade dos procedimentos e efetiva busca da justiça no caso concreto." 20

Por último, o princípio da efetividade ou da supremacia do interesse social no Processo que, de acordo com Rui Portanova ${ }^{21}$ :

Trata-se de um princípio de direito público que norteia o Estado em duas grandes direções: de um lado, a proteção dos direitos e garantias individuais, expressa principalmente pelo princípio da legalidade; por outro, a satisfação de interesses públicos para a qual se constitui Administração Pública.

Dos Princípios informativos de terceiro grau derivam, por óbvio, os Princípios de segundo grau: juiz natural, acesso ao judiciário e devido processo legal. Destes, por sua vez, decorrem os Princípios de primeiro grau.

Do princípio do juiz natural decorrem: inércia da jurisdição, independência, imparcialidade, inafastabilidade, gratuidade judiciária, investidura, aderência ao território, indelegabilidade, indeclinabilidade, independência da jurisdição civil e criminal.

O acesso ao judiciário origina os seguintes Princípios: demanda, autonomia da ação, dispositivo, ampla defesa, defesa global, eventualidade, estabilidade objetiva da demanda, estabilidade subjetiva da demanda, perpertuatio jurisdictione e recursividade.

No princípio do Devido Processo Legal encontram amparo: impulso oficial, Contraditório, publicidade, finalidade, prejuízo, busca da verdade, licitude da prova, avaliação da prova, livre convencimento, persuasão racional, duplo grau de jurisdição e fungibilidade do recurso. 


\section{NORMAS FUNDAMENTAIS NO NOVO CPC}

A Lei 13.105/2015 traz, não somente alterações no Direito Processual Civil brasileiro, mas sim um verdadeiro novo Código. Com uma nova ideologia, buscando realmente a concretização de um verdadeiro Estado Democrático de Direito.

Para alcançar tal concretização, o legislador iniciou o texto legal impondo "NORMAS FUNDAMENTAIS" que direcionarão a atividade jurisdicional.

Desta feita, analisar-se-á alguns dos princípios que compõem o capítulo 1 do Novo Código de Processo Civil (Lei 13.105/2015).

\subsection{Interpretação conforme a Constituição da República Federativa do Brasil}

Dispõe o artigo $1^{\circ}$ : O processo civil será ordenado, disciplinado e interpretado conforme os valores e as normas fundamentais estabelecidos na Constituição da República Federativa do Brasil, observando-se as disposições deste Código.

A necessidade de serem estabelecidas novas bases para a construção de um novo pensamento contemporâneo do direito processual civil é algo imprescindível. Pois é a partir da Constituição Federal que se deve buscar compreender o que é, para que serve e como funciona o direito processual civil. ${ }^{22}$

Destaca Luis Guilherme Marinoni que:

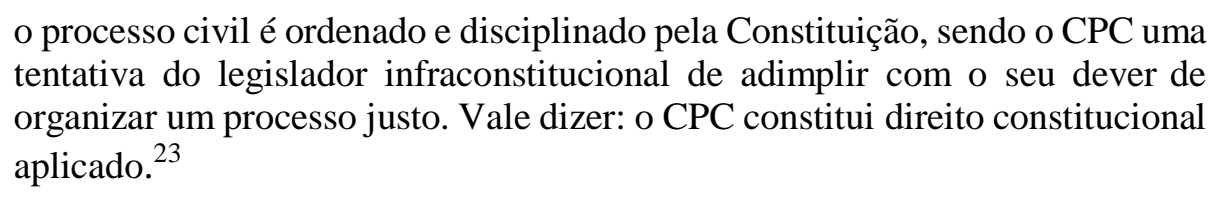

Assim, o legislador, voltado à necessidade de compatibilização entre o texto infraconstitucional com a Carta Magna, inicia o texto legal dispondo que o Processo Civil será embasado pelos valores estabelecidos na Constituição da República Federativa do Brasil. 


\subsection{Princípio do Dispositivo}

Já o artigo $2^{\circ}$ tem a seguinte redação: $O$ processo começa por iniciativa da parte e se desenvolve por impulso oficial, salvo as exceções previstas em lei.

No sistema inquisitivo puro o juiz é colocado como a figura principal do processo, cabendo a ele a sua instauração e condução sem a necessidade de qualquer provocação das partes. A liberdade de atuação do juiz é ampla e irrestrita. No sistema dispositivo puro o juiz passa a ater uma participação condicionada à vontade das partes, que definem não só a existência e extensão do processo - cabendo ao interessado a sua propositura e definição dos elementos objetivos e subjetivos -, como também o seu desenvolvimento, que dependerá de provocação para que prossiga. $^{24}$

Chama-se poder dispositivo a liberdade que as pessoas têm de exercer ou não seus direitos. Em direito processual tal poder é configurado pela possibilidade de apresentar ou não sua pretensão em juízo, bem como de apresentá-la da maneira que melhor lhes aprouver e renunciar a ela (desistir da ação) ou de certas situações processuais. Trata-se do princípio da disponibilidade processual. ${ }^{25}$

A jurisdição é inerte no sentido de que ela não é prestada de ofício. Os interessados no exercício da função jurisdicional devem requerê-la, devem provocar a atuação do Estado-juiz. ${ }^{26}$

O sistema brasileiro é um sistema misto, com preponderância do princípio dispositivo $^{27}$. Diante disto, o legislador, no artigo $2^{\circ}$, consagrou o Princípio da Inércia ${ }^{1}$ ou Princípio Dispositivo. As exceções devem estar previstas em lei. 
Assim, o artigo $2^{\circ}$ do NCPC ao lado dos artigos 141, 190 e 492 do CPC, formam o conteúdo daquilo que a doutrina costuma chamar de princípio da demanda (ou princípio dispositivo em sentido material). ${ }^{28}$

\title{
4.3 Princípio da Inafastabilidade do Controle Jurisdicional
}

Dispõe o artigo $3^{\circ}$ :

\begin{abstract}
Não se excluirá da apreciação jurisdicional ameaça ou lesão ao direito. $\$ 1^{\circ}$ É permitida a arbitragem, na forma da lei.

$\$ 2^{\circ}$ O Estado promoverá, sempre que possível, a solução consensual dos conflitos.

$\$ 3^{\circ}$ A conciliação, a mediação e outros métodos de solução consensual de conflitos deverão ser estimulados por juízes, advogados, defensores públicos e membros dos Ministério Público, inclusive no curso do processo judicial.
\end{abstract}

Este artigo disciplinando que "Não se excluirá da apreciação jurisdicional ameaça ou lesão a direito", repete o princípio insculpido no art. $5^{\circ}, \mathrm{XXXV}$, da Constituição da República Federativa do Brasil.

O Princípio da Inafastabilidade do Controle Jurisdicional impede que o legislador restrinja o acesso à ordem jurídica ou ao ordenamento justo, bem como impõe ao juiz o dever de prestar a jurisdição, isto é, garantir a tutela efetiva, a quem detenha uma posição jurídica de vantagem. ${ }^{29}$

Não se trata, portanto, de mera garantia de acesso ao juízo, mas da própria tutela jurisdicional a quem tiver razão. Em outras palavras, significa o próprio Acesso à Justiça. Frisese, no entanto, que este direito à prestação jurisdicional não é incondicional e genérico, sujeitando-se a condições da legislação processual e do direito substantivo. ${ }^{30}$

\footnotetext{
${ }^{1}$ Alguns doutrinadores entendem a Inércia como característica da Jurisdição.
} 
É por essa razão que o novo Código, além de prever procedimentos diferenciados ao lado do procedimento comum, introduz várias técnicas processuais no procedimento comum capazes de moldar o processo às necessidades do direito material afirmado em juízo. Por essa razão é que o novo Código prevê, por exemplo, distribuição adequada do ônus da prova, inclusive com possibilidade de inversão (art. 373), técnicas antecipatórias idôneas a distribuir isonomicamente o ônus do tempo do processo, seja em face da urgência (arts. 300 a 310), seja em face da evidência (art. 311), de formas de tutela jurisdicional com executividade intrínseca (arts. 536 a 538) e técnicas executivas atípicas (arts. 139, IV, 536 a 538). ${ }^{31}$

$\mathrm{O} \S 1^{\circ}$ deste artigo disciplina que "É permitida a arbitragem, na forma da lei."

A arbitragem consiste na solução do conflito por meio de um terceiro escolhido pelas partes, com poder de decisão, segundo normas e procedimentos aceitos por livre e espontânea vontade das partes. A arbitragem é um procedimento equivalente à Jurisdição, um procedimento paraestatal.

Após alguma discussão na doutrina e jurisprudência, venceu a tese de que a arbitragem não afronta o Princípio da Inafastabilidade da Jurisdição, pois se o próprio direito de ação é disponível, dependendo da vontade do interessado para se concretizar por meio da propositura da demanda judicial, também o será o exercício da jurisdição na solução do conflito de interesse. $^{32}$

Já os parágrafos $2^{\circ}$ e $3^{\circ}$ disciplinam respectivamente: "O Estado promoverá, sempre que possível, a solução consensual dos conflitos", e "A conciliação, a mediação e outros métodos de solução consensual de conflitos deverão ser estimulados por juízes, advogados, defensores públicos e membros do Ministério Público, inclusive no curso do processo judicial".

Segundo Fernando Gajardoni ${ }^{33}$ :

O Novo CPC, de modo absolutamente correto, aposta muitas de suas fichas na solução consensual dos conflitos. O texto base, aprovado no Senado, usa as expressões "mediação" e "conciliação" ao menos 44 (quarenta e quatro) vezes, colocando, entre as normas fundamentais do processo civil, o dever do Estado de incentivar a solução consensual dos conflitos (art. $3^{\circ}, \S \S 2^{\circ}$ e $3^{\circ}$ do CPC/2015).

Assim, uma das grandes virtudes do novo Código de Processo Civil é o estímulo aos métodos alternativos de solução de conflitos, em especial à conciliação e à mediação. $\mathrm{O}$ desafio proposto pelo novo Código de Processo Civil é hercúleo, porque almeja a transformação de nossa sociedade, da cultura do litígio para a cultura do consenso. ${ }^{34}$ 


\title{
4.4 Princípio da duração razoável do processo
}

Dispõe o art. $4^{\circ}$ do novo CPC: "As partes têm o direito de obter em prazo razoável a solução integral do mérito, incluída a atividade satisfativa”.

Há que se considerar preliminarmente que o direito à duração razoável do processo não constitui e não implica direito a processo rápido e célere. As expressões não são sinônimas.

\begin{abstract}
A natureza necessariamente temporal do processo constitui imposição democrática, oriunda do direito das partes de nele participarem de forma adequada, donde o direito ao contraditório e os demais direitos que confluem para organização do processo justo ceifam qualquer possibilidade de compreensão do direito ao processo como direito ao processo célere. $\mathrm{O}$ que a Constituição e o novo Código determinam é a eliminação do tempo patológico - a desproporcionalidade entre a duração do processo e a complexidade do debate da causa que nele tem lugar. $\mathrm{O}$ direito ao processo justo implica direito ao processo sem dilações indevidas, que se desenvolva temporalmente dentro de um tempo justo. ${ }^{35}$
\end{abstract}

Com a Emenda Constitucional 45/2004, o direito a um processo sem dilações indevidas foi expressamente alçado à qualidade de direito fundamental. Deve ser lembrado que a celeridade nem sempre é possível. O legislador não pode sacrificar direitos fundamentais das partes visando somente a obtenção de celeridade processual, sob pena de criar situações ilegais e injustas. ${ }^{36}$

Embora o legislador tenha criado diversos mecanismos ${ }^{2}$ processuais voltados a um processo mais rápido, necessário se faz que o Poder Judiciário esteja voltado à prestação da tutela jurisdicional sem quaisquer dilações indevidas, a fim de que se alcance verdadeira justiça.

\subsection{Princípio da Boa-fé e lealdade processual}

Os deveres de proceder com lealdade e com boa-fé, esculpidos no art. $5^{\circ}$ nos seguintes termos: "Aquele que de qualquer forma participa do processo deve comportar-se de acordo com a boa-fé”, prestam-se a evitar os exageros no exercício da ampla defesa.

\footnotetext{
${ }^{2}$ Por exemplo: o julgamento antecipado do mérito (art. 355), procedimento monitório (art. 700), etc.
} 
A boa-fé pode se reconduzida à segurança jurídica, na medida em que é possível reduzi-la dogmaticamente à necessidade de proteção à confiança legítima - que constitui um dos elementos do princípio da segurança jurídicade prevalência da materialidade no trafégo jurídico. ${ }^{37}$

Assim, a ausência da boa-fé pode levar, conforme o caso, à ineficácia do ato processual contrário à boa-fé, à responsabilização por dano processual e inclusive à sanção pecuniária.

Sem dúvida, são inerentes à boa-fé os deveres das partes de veracidade e de lealdade na prática dos atos processuais. Mas o grande mérito do dispositivo é o de estabelecer o dever de boa-fé para todos, o que inclui, obviamente e com maior razão, o Estado-Juiz. Nessa medida, a adoção da jurisprudência defensiva viola frontalmente o disposto nos arts. $5^{\circ}$ e $6^{\circ}$ do novo CPC. ${ }^{38}$

\title{
4.6 Princípio da Cooperação/ colaboração
}

$\mathrm{O}$ art. $6^{\circ}$ traz o Princípio da Cooperação nos seguintes termos: "Todos os sujeitos do processo devem cooperar entre si para que se obtenha, em tempo razoável, decisão de mérito justa e efetiva".

Um dos grandes problemas do processo está na equilibrada organização de seu formalismo, ou seja, da divisão do trabalho entre os participantes.

\begin{abstract}
A adequada construção do modelo cooperativo de processo e do princípio da colaboração que é a ele inerente servem de linhas centrais para organização de um processo civil que reflita de forma efetiva os pressupostos culturais do Estado Constitucional. A colocação da colaboração nesses dois patamares visa a destacar, portanto, a necessidade de entendê-la como o eixo sistemático a partir do qual se pode estruturar um processo justo do ponto de vista da divisão do trabalho entre o juiz e as partes no processo civil. ${ }^{39}$
\end{abstract}

Esse princípio, portanto, estrutura-se a partir da previsão de regras que devem ser seguidas pelo juiz na condução do processo. O juiz tem deveres de esclarecimentos, de diálogo, de prevenção e de auxílio para com os litigantes. Esses deveres unidos as regras estão sendo enunciados quando se fala em colaboração no processo. ${ }^{40}$ 


\subsection{Princípio da Igualdade}

$\mathrm{O}$ art. $7^{\circ}$ traz o Direito a igualdade no processo civil: “É assegurado às partes paridade de tratamento em relação ao exercício de direitos e faculdades processuais, aos meios de defesa, aos ônus, aos deveres e à aplicação de sanções processuais, competindo ao juiz zelar pelo efetivo contraditório".

O Princípio da igualdade perante o Estado Constitucional é pressuposto básico de toda e qualquer concepção jurídica do Estado.

Trata-se de direito fundamental que, nada obstante não previsto expressamente na Constituição para o campo do processo, decorre naturalmente da ideia de Estado Constitucional e do direito fundamental à igualdade perante a ordem jurídica como um todo. (art. $5^{\circ}$, caput, $\mathrm{CF}$ ).

A igualdade no processo precisa ser vista sob duas perspectivas distintas:

a) "Importa ter presente a distinção entre igualdade perante a legislação (igualdade formal) e igualdade na legislação (igualdade material)".

b) "É preciso ressaltar a diferença entre igualdade no processo e igualdade pelo processo- igualdade diante do resultado da aplicação da legislação no processo". ${ }^{41}$

\subsection{Princípio da Dignidade da Pessoa Humana}

$\mathrm{O}$ art. $8^{\circ}$ traz a garantia do Princípio da Dignidade da Pessoa Humana: “Ao aplicar o ordenamento jurídico, o juiz atenderá aos fins sociais e às exigências do bem comum, resguardando e promovendo a dignidade da pessoa humana e observando a proporcionalidade, a razoabilidade, a legalidade, a publicidade e a eficiência".

Verifica-se que o artigo $8^{\circ}$ do novo CPC salienta a necessidade do juiz aplicar o ordenamento jurídico resguardando e promovendo a dignidade da pessoa humana, que constitui um dos fundamentos do Estado Constitucional, previsto no artigo $1^{\circ}$, inciso III da CF.

A dignidade humana, portanto determina a compreensão de um processo civil como um meio para tutela de direitos.

Em outras palavras, o processo civil serve para realização dos direitos e para orientação das pessoas a respeito do significado do direito. 
A dignidade humana conecta-se com o direito à liberdade e à autonomia privada, o que explica a necessidade de respeito, dentro dos limites constitucionais e legais aos negócios processuais realizados entre as partes (art. 190) e constitui estímulo à realização de calendários processuais entre o juiz e as partes como instrumento para eficiente gestão em tempo no processo civil (art. 191). ${ }^{42}$

Por fim, a dignidade da pessoa humana veda a transformação das partes em objeto da atividade jurisdicional. É por essa razão que a dignidade da pessoa humana tem estreita ligação com o direito de participação das partes na construção dos provimentos jurisdicionais - isto é, na previsão do direito ao contraditório e do dever de fundamentação. ${ }^{43}$

\subsection{Princípio do Contraditório}

Este princípio se apresenta como característica fundamental do processo, já que para o Estado Constitucional Brasileiro a construção da decisão judicial deve dar-se através de um procedimento que se realiza com total observância de um contraditório efetivo. ${ }^{44}$

O princípio do contraditório deve ser compreendido como dupla garantia: a de efetiva participação (com possibilidade de influência na formação do resultado) e a de não surpresa.

As decisões judiciais devem ser fruto de amplo debate entre todos os participantes do processo. Não pode ela ser resultado do livre arbítrio (convencimento) do magistrado. Não se admite que o resultado do processo seja fruto do "solipsismo do juiz".

Lênio Streck $^{45}$ ao tratar do solipsismo do juiz afirma:

Decidir não é escolher. Escolhas são da ordem de nossa razão prática. Escolhese entre ir ao cinema ou ao futebol. Mas quando o juiz decide (judicialmente falando) deve fazê-lo a partir do Direito. Evidente que a decisão não é um ato subsuntivo (a subsunção sequer se sustenta filosoficamente; subsunção é tão fictícia quanto a sustentação da verdade real). Mas a decisão tampouco é um ato arbitrário. O juiz não é escravo da lei.... Óbvio isso. Mas, por favor, ele tampouco é dono da lei (ou da Constituição ou do conceito de religião ou do conceito de cultura ou do conceito de preconceito ou do conceito de discurso de ódio).

As decisões judiciais só são legítimas quando produzidas com respeito ao contraditório prévio, efetivo e dinâmico. Por isso que o artigo $9^{\circ}$ expressamente dispõe que não se proferirá decisão contra uma das partes sem que as partes sejam ouvidas previamente, pois assim, não haverá a violação do contraditório. Há, porém, três exceções onde há o contraditório diferido ou postergado. O primeiro caso é o caso da tutela provisória de urgência que impõe o 
deferimento inaudita altera pars (art. 9, parágrafo único, I). A segunda exceção é no caso de tutela de evidência firmada em contrato de depósito, comprovado documentalmente, onde se determina a entrega imediata da coisa depositada sob pena de cominação de multa. (art. 9, parágrafo único, II). A última exceção é a decisão que determina a expedição do mandado monitório, onde existe a chamada inversão de iniciativa do contraditório. Neste caso só haverá contraditório pleno, caso o demandado optar por oferecer os embargos, sem os quais constituirse-á de pleno direito o título executivo judicial (Arts. 701 e 702).

Consequência do contraditório substancial ${ }^{3}$ é que deve ser ele, também, compreendido como uma garantia de não surpresa. Culturalmente, no Brasil sempre se admitiu a prolação de decisões fundadas em argumentos de direito que não tivessem sido submetidos a debate prévio. É exigência do Estado Democrático de Direito o exercício do poder estatal de forma comparticipativa, já que a participação da sociedade é um dos elementos integrantes dessa forma de Estado expressamente estabelecida pela Constituição da República ${ }^{46}$.

\section{CONSIDERAÇÕES FINAIS}

A Constituição Federal de 1988 trouxe consigo normas relacionadas ao processo civil para garantir a todos os indivíduos o acesso à justiça. O novo CPC traz no seu Livro I, Capítulo I uma parte dedicada "As Normas Fundamentais do Processo Civil”, demonstrando a sintonia entre o texto constitucional e a novel legislação processual.

Verificou-se, assim, na presente pesquisa que a onda de constitucionalização dos direitos foi sedimentada no processo civil atual com a introdução dos princípios constitucionais processuais no texto do novo Código de Processo Civil brasileiro.

Para alcançar tal objetivo analisou-se os direitos fundamentais na Constituição Federal de 1988, discorreu-se brevemente sobre a teoria dos princípios e regras, analisou-se os princípios processuais constitucionais e por fim, elencou-se algumas das normas fundamentais dispostas no Capítulo I da Lei 13.105/2015.

Por tudo isso, há de se perceber que a vigência do novo código processual civil trará um impacto profundo na maneira como a prática do direito se concretiza, especialmente, em sua perspectiva fundamental.

\footnotetext{
${ }^{3}$ Aquele que garante a participação com influência.
} 


\section{REFERÊNCIAS DAS FONTES CITADAS}

ALEXY, Robert. Direitos Fundamentais, ponderação e racionalidade. Revista de Direito Privado. RDPriv 24/334. Out-dez. 2005

BARROSO, Luís Roberto. Interpretação e aplicação da constituição. São Paulo: Saraiva, 1996.

BUENO, Cassio Scarpinella. Curso sistematizado de Direito Processual Civil. São Paulo: Saraiva, 2007. p. 83

CÂMARA, Alexandre Freitas. O Novo processo civil brasileiro. São Paulo: Atlas, 2015.

CANOTILHO, J.J. Gomes. Constitucional e teoria da constituição. $7^{\text {a }}$ ed. Coimbra: Portugal: Almedina, 2003.

CINTRA, Antonio Carlos de Araújo. GRINOVER, Ada Pelegirni. DINAMARCO, Cândido Rangel. Teoria Geral do Processo. 22 $2^{\mathrm{a}}$ Ed. São Paulo: Editora Malheiros, 2006.

CRUZ, Paulo Márcio; GOMES, Rogério Zuel. Princípios constitucionais e direitos fundamentais. Contribuições ao debate. Curitiba: Juruá, 2007.

DOTTI, Rogério. Novo CPC dá prioridade ao diálogo, à boa-fé e à justiça do caso.

Disponível em: http://www.conjur.com.br/2015-mai-11/direito-civil-atual-cpc-prioridadedialogo-boa-fe-justica. Consultado em 29 de março de 2016.

FERRAJOLI, Luigi. Por uma Teoria dos Direitos e dos Bens Fundamentais. Tradução de Alexandre Salim, Alfredo Copetti Neto, Daniela Cademartori, Hermes Zaneti Júnior, Sérgio Cademartori. Porto Alegre:Livraria do Advogado, 2011.

GUASTINI, Riccardo. Das fontes às normas. Tradução de Edson Bini. São Paulo: Editora Quartier Latin do Brasil, 2005.

GAJARDONI, Fernando da Fonseca. Novo CPC: Vale apostar na conciliação/mediação? Disponível em: http://jota.info/novo-cpc-vale-apostar-na-conciliacaomediacao. Consultado em 29 de março de 2016.

LIMA, Flávio Pereira. Reflexões sobre o novo CPC: a mediação e a advocacia. Disponível em: jota.info/reflexoes-sobre-o-novo-cpc-a-mediacao-e-a-advocacia. Consultado em 29 de março de 2016.

MARINONI, Luiz Guilherme. ARENAHART, Sérgio Cruz. MITIDIERO, Daniel. Novo Código de Processo civil comentado. São Paulo: Revista dos tribunais, 2015. 
NEVES, Daniel Amorim Assumpção. Manual de Direito Processual Civil. São Paulo: Método, 2014.

PASOLD, Cesar Luiz. Prática da Pesquisa jurídica e Metodologia da pesquisa jurídica. 10 ed. Florianópolis: OAB-SC editora, 2007.

PINHO, Humberto Dalla Bernardina de. Direito Processual Civil Contemporâneo. Volume 1. São Paulo: Saraiva, 2012.

PISARELLO, Gerardo. Los derechos sociales y sus garantias. Elementos para uma reconstrución. 2007.

PORTANOVA, Rui. Princípios do Processo Civil. Porto Alegre: Livraria do Advogado Editora.2003.

SILVA, Ovídio Baptista da; GOMES, Fábio. Teoria geral do processo. 3. Ed. São Paulo: RT, 2002.

STRECK, Lênio. O juiz, a umbanda e o solipsismo: como ficam os discursos de intolerância? Disponível em: http://www.conjur.com.br/2014-mai-22/juiz-umbandasolipsismo-ficam-discursos-intolerancia. Consultado em 26 de março de 2016.

1 “[...] momento no qual o Pesquisador busca e recolhe os dados, sob a moldura do Referente estabelecido[...]. PASOLD, Cesar Luiz. Prática da Pesquisa jurídica e Metodologia da pesquisa jurídica. 10 ed. Florianópolis: OAB-SC editora, 2007. p. 101.

2 “[...] pesquisar e identificar as partes de um fenômeno e colecioná-las de modo a ter uma percepção ou conclusão geral [...]". PASOLD, Cesar Luiz. Prática da Pesquisa jurídica e Metodologia da pesquisa jurídica. p. 104.

${ }^{3}$ Sobre os métodos e técnicas nas diversas fases da Pesquisa Científica, vide PASOLD, Cesar Luiz.

Prática da Pesquisa Jurídica, op. cit.. especialmente, p. 99-107.

4 “[...] palavra ou expressão estratégica à elaboração e/ou à expressão de uma idéia." PASOLD, Cesar Luiz. Prática da Pesquisa jurídica e Metodologia da pesquisa jurídica. p. 31 .

5 “[...] uma definição para uma palavra ou expressão, com o desejo de que tal definição seja aceita para os efeitos das ideias que expomos [...]”. PASOLD, César Luiz. Prática da Pesquisa jurídica e Metodologia da pesquisa jurídica. p. 45.

6 “Técnica de investigação em livros, repertórios jurisprudenciais e coletâneas legais. PASOLD, César Luiz. Prática da Pesquisa jurídica e Metodologia da pesquisa jurídica. p. 239.

${ }^{7}$ FERRAJOLI, Luigi. Por uma Teoria dos Direitos e dos Bens Fundamentais. Tradução de Alexandre Salim, Alfredo Copetti Neto, Daniela Cademartori, Hermes Zaneti Júnior, Sérgio Cademartori. Porto Alegre:Livraria do Advogado, 2011. p.15.

${ }^{8}$ FERRAJOLI, Luigi. Por uma Teoria dos Direitos e dos Bens Fundamentais. Tradução de Alexandre Salim, Alfredo Copetti Neto, Daniela Cademartori, Hermes Zaneti Júnior, Sérgio Cademartori. Porto Alegre:Livraria do Advogado, 2011. p.10.

${ }^{99}$ PISARELLO, Gerardo. Los derechos sociales y sus garantias. Elementos para uma reconstrución. 2007, p. 80.

${ }^{10}$ BARROSO, Luís Roberto. Interpretação e aplicação da constituição. São Paulo: Saraiva, 1996. p. 141. 
${ }^{11}$ CANOTILHO, J.J. Gomes. Constitucional e teoria da constituição. $7^{\mathrm{a}}$ ed. Coimbra: Portugal: Almedina, 2003. p. 1160.

${ }^{12}$ GUASTINI, Riccardo. Das fontes às normas. Tradução de Edson Bini. São Paulo: Editora Quartier Latin do Brasil, 2005. p. 185-186.

${ }^{13}$ CANOTILHO, J.J. Gomes. Constitucional e teoria da constituição. $7^{\text {a }}$ ed. Coimbra: Portugal: Almedina, 2003. p. 1160 - 1161.

${ }^{14}$ GUASTINI, Riccardo. Das fontes às normas. Tradução de Edson Bini. São Paulo: Editora Quartier Latin do Brasil, 2005. p. 186-188.

${ }^{15}$ GUASTINI, Riccardo. Das fontes às normas. Tradução de Edson Bini. São Paulo: Editora Quartier Latin do Brasil, 2005. p.191-193.

${ }^{16}$ CRUZ, Paulo Márcio; GOMES, Rogério Zuel. Princípios constitucionais e direitos fundamentais. Contribuições ao debate. Curitiba: Juruá, 2007. p. 27.

${ }^{17}$ CRUZ, Paulo Márcio; GOMES, Rogério Zuel. Princípios constitucionais e direitos fundamentais. Contribuições ao debate. Curitiba: Juruá, 2007. p. 27-29.

${ }^{18}$ ALEXY, Robert. Direitos Fundamentais, ponderação e racionalidade. Revista de Direito Privado. RDPriv 24/334. Out-dez. 2005

${ }^{19}$ PORTANOVA, Rui. Princípios do Processo Civil. Porto Alegre: Livraria do Advogado Editora. 2003. p. 19.

${ }^{20}$ PORTANOVA, Rui. Princípios do Processo Civil. Porto Alegre: Livraria do Advogado Editora. 2003. p. 48.

${ }^{21}$ PORTANOVA, Rui. Princípios do Processo Civil. Porto Alegre: Livraria do Advogado Editora. 2003. p. 56.

${ }^{22}$ BUENO, Cassio Scarpinella. Curso sistematizado de Direito Processual Civil. São Paulo: Saraiva, 2007. p. 83

${ }^{23}$ MARINONI, Luiz Guilherme. ARENAHART, Sérgio Cruz. MITIDIERO, Daniel. Novo Código de Processo civil comentado. São Paulo: Revista dos tribunais, 2015. P.91.

${ }^{24}$ NEVES, Daniel Amorim Assumpção. Manual de Direito Processual Civil. São Paulo: Método, 2014. p. 86.

${ }^{25}$ CINTRA, Antonio Carlos de Araújo. GRINOVER, Ada Pelegirni. DINAMARCO, Cândido Rangel. Teoria Geral do Processo. $22^{\text {a }}$ Ed. São Paulo: Editora Malheiros, 2006. P. 66

${ }^{26}$ BUENO, Cassio Scarpinella. Curso sistematizado de Direito Processual Civil. São Paulo: Saraiva, 2007. p. 248

${ }^{27}$ SILVA, Ovídio Baptista da; GOMES, Fábio. Teoria geral do processo. 3. Ed. São Paulo: RT, 2002. p. 47.

${ }^{28}$ MARINONI, Luiz Guilherme. ARENAHART, Sérgio Cruz. MITIDIERO, Daniel. Novo Código de Processo civil comentado. São Paulo: Revista dos tribunais, 2015. P.93.

${ }^{29}$ PINHO, Humberto Dalla Bernardina de. Direito Processual Civil Contemporâneo. Volume 1. São Paulo: Saraiva, 2012. p. 98.

${ }^{30}$ PINHO, Humberto Dalla Bernardina de. Direito Processual Civil Contemporâneo. Volume 1. São Paulo: Saraiva, 2012. p. 99.

${ }^{31}$ MARINONI, Luiz Guilherme. ARENAHART, Sérgio Cruz. MITIDIERO, Daniel. Novo Código de Processo civil comentado. São Paulo: Revista dos tribunais, 2015. P.95.

${ }^{32}$ NEVES, Daniel Amorim Assumpção. Manual de Direito Processual Civil. São Paulo: Método, 2014. p. 12.

33 GAJARDONI, Fernando da Fonseca. Novo CPC: Vale apostar na conciliação/mediação? Disponível em: http://jota.info/novo-cpc-vale-apostar-na-conciliacaomediacao. Consultado em 29 de março de 2016.

${ }^{34}$ LIMA, Flávio Pereira. Reflexões sobre o novo CPC: a mediação e a advocacia. Disponível em: jota.info/reflexoes-sobre-o-novo-cpc-a-mediacao-e-a-advocacia. Consultado em 29 de março de 2016.

${ }_{35}$ MARINONI, Luiz Guilherme. ARENAHART, Sérgio Cruz. MITIDIERO, Daniel. Novo Código de Processo civil comentado. São Paulo: Revista dos tribunais, 2015. P.97

${ }^{36}$ NEVES, Daniel Amorim Assumpção. Manual de Direito Processual Civil. São Paulo: Método, 2014. p. 97.

${ }^{37}$ MARINONI, Luiz Guilherme. ARENAHART, Sérgio Cruz. MITIDIERO, Daniel. Novo Código de Processo civil comentado. São Paulo: Revista dos tribunais, 2015. P.99

${ }^{38}$ DOTTI, Rogério. Novo CPC dá prioridade ao diálogo, à boa-fé e à justiça do caso. Disponível em: 
http://www.conjur.com.br/2015-mai-11/direito-civil-atual-cpc-prioridade-dialogo-boa-fe-justica. Consultado em 29 de março de 2016.

${ }^{39}$ MARINONI, Luiz Guilherme. ARENAHART, Sérgio Cruz. MITIDIERO, Daniel. Novo Código de Processo civil comentado. São Paulo: Revista dos tribunais, 2015. P.100.

${ }^{40}$ MARINONI, Luiz Guilherme. ARENAHART, Sérgio Cruz. MITIDIERO, Daniel. Novo Código de Processo civil comentado. São Paulo: Revista dos tribunais, 2015. P.100.

${ }^{41}$ MARINONI, Luiz Guilherme. ARENAHART, Sérgio Cruz. MITIDIERO, Daniel. Novo Código de Processo civil comentado. São Paulo: Revista dos tribunais, 2015. P.103.

${ }^{42}$ MARINONI, Luiz Guilherme. ARENAHART, Sérgio Cruz. MITIDIERO, Daniel. Novo Código de Processo civil comentado. São Paulo: Revista dos tribunais, 2015. P.105

${ }^{43}$ MARINONI, Luiz Guilherme. ARENAHART, Sérgio Cruz. MITIDIERO, Daniel. Novo Código de Processo civil comentado. São Paulo: Revista dos tribunais, 2015. P.106

${ }^{44}$ CÂMARA, Alexandre Freitas. O Novo processo civil brasileiro. São Paulo: Atlas, 2015. p. 8.

${ }^{45}$ STRECK, Lênio. O juiz, a umbanda e o solipsismo: como ficam os discursos de intolerância? Disponível em: http://www.conjur.com.br/2014-mai-22/juiz-umbanda-solipsismo-ficam-discursosintolerancia. Consultado em 26 de março de 2016.

${ }^{46}$ CÂMARA, Alexandre Freitas. O Novo processo civil brasileiro. São Paulo: Atlas, 2015. p. 11-12. 